\title{
A Contribuição do Cão Terapeuta no Ambiente Hospitalar
}

\author{
Aluani, Erminda P.; Machado, Ana Carolina A.; Trindade, Ivani C.; Hipólito, Priscila \\ S. Aono; Correia, Emmanoela Camila V. S. \\ Hospital Geral de Itapevi — dir.assist@hgi.org.br
}

Introdução a utilização de animais em ambientes hospitalares ocorre com frequência nos Estados Unidos e da Europa há várias décadas. no Brasil, o método foi introduzido no final da década de noventa. a TAA (Terapia assistida por animais) é comprovada cientificamente pelas suas grandes contribuições e, em nossa unidade, no ano de 2013 , foi prática relevante no controle da dor e nos processos de reabilitação de crianças. Objetivos Os principais objetivos do projeto são: contribuir na melhoria do quadro clínico dos pacientes, facilitando seu relacionamento com o ambiente hospitalar e sua doença, a partir do entretenimento, motivação e bem estar, fundamentada na Atividade Assistida por Animais. Método Os animais que participam do projeto recebem treinamento especial e passam por rigorosa avaliação comportamental, onde seu desempenho é reavaliado a cada visita. Sua saúde é acompanhada por médicos veterinários, mantendo vacinação e vermifugação em dia, bem como perfeitas condições psicobiológicas para uma boa relação terapêutica. o projeto é realizado com visitas programadas após avaliação criteriosa do animal, e consentimento da visita pelos pacientes, de acordo com a avaliação de gravidade/criticidade de cada um dos casos clínicos. Foram traçados planos de contingência para que não ocorram acidentes com os animais nas visitas monitoradas. o projeto foi revisado e validado pelo Serviço de Controle de Infecção Hospitalar. no HGI, o cão-terapeuta é identificado por meio de um crachá semelhante ao utilizados pelos colaboradores, e possui uma lista de controle de sua presença no hospital, onde as patas coloridas representam sua assinatura. a terapia com o cão não promete a cura de doenças, mas promove benefícios fisiológicos e psicológicos. Resultados Entre os resultados encontrados após as visitas acontecerem mensalmente nas unidades de pediatria, clínica médica e cirúrgica foi verificada a diminuição de medicações administradas no período da visita. As medicações prescritas como administração "se necessário", da classe analgésicos, diminuíram $90,47 \%$ com a presença do cão-terapeuta, avaliando-se somente o último semestre (março/2013 - agosto/2013). a unidade pediátrica conta com 34 leitos. no período de análise, a média de prescrições médicas foi de 21 pacientes/dia, sendo administrada analgesia somente em duas crianças no período de visita. Outros resultados mais subjetivos foram observados em todas as unidades visitadas pelo cão. Conclusões: a presença do cão-terapeuta promove a humanização e harmonização do ambiente, contribuindo para a recuperação do paciente, resgatando sua autoestima e autoconfiança, o que possibilita melhorar as condições clínicas sob os aspectos fisiológicos e psicológicos. um dos objetivos alcançado com o projeto Acãolhimento foi divertir e entreter o paciente, familiares e equipe multiprofissional inseridos no contexto hospitalar.

Aluani, Erminda P.; Machado, Ana Carolina A.; Trindade, Ivani C.; Hipólito, Priscila S. Aono; Correia, Emmanoela Camila V. S.. A Contribuição do Cão Terapeuta no Ambiente Hospitalar. In: Anais do Congresso Internacional de Humanidades \& Humanização em Saúde [= Blucher Medical Proceedings, num.2, vol.1]. São Paulo: Editora Blucher, 2014. ISSN 2357-7282

DOI 10.5151/medpro-cihhs-10609 